\title{
Membaca Struktur, Mencari Makna: \\ Suatu Usaha Memahami Konstruksi Budaya
}

\author{
Hendra Kaprisma \\ Faculty of Humanities Universitas Indonesia \\ kaprisma@ui.ac.id
}

\begin{abstract}
Studi mengenai struktur dan fungsi, khususnya dalam teori-teori sosiologi kontemporer mengantarkan manusia pada pemahaman mendasar terhadap nilai-nilai kehidupan secara keseluruhan. Struktur mengacu pada seperangkat unit sosial yang relatif stabil dan berpola, sedangkan fungsi mengacu pada proses dinamis yang terjadi dalam struktur tersebut. Fungsi-fungsi mengandaikan terjadinya antar-hubungan, sebaliknya, antarhubungan mengevokasi perubahan fungsi. Pada dasarnya, struktur sudah mengimplikasikan antar-hubungan sekaligus fungsi. Sebaliknya, dalam mengartikan teori budaya tidak ada definisi yang secara umum dapat disepakati. Hal itu dikarenakan teori budaya bukanlah ilmu yang ditentukan oleh seperangkat aturan dan prosedur yang baku. Dalam kenyataannya, teori tersebut merupakan setumpuk wacana yang merangkum beragam tema dan pendekatan. Isu-isu yang dikaji oleh teori budaya tidak hanya mencerminkan konsentrasi terhadap salah satu disiplin ilmu yang berdiri sendiri. Teori budaya telah merumuskan kembali batas-batas disipliner yang telah lama diikuti dengan strategi mempertemukan bidangbidang kajian yang berlainan. Pada perkembangannya, teori budaya menciptakan ruang bagi pertukaran kreatif antar wilayah pengetahuan. Dengan demikian, dapat dikatakan bahwa teori budaya mendorong munculnya perspektif baru dan mewadahi perkembangan perspektif tersebut sebagai wujud interdisiplineritas dalam tumbuh-kembang penjelajahan intelektualitas.
\end{abstract}

Keywords: budaya; fungsi; konstruksi; struktur. 


\section{INTRODUCTION}

"Culture is the system of shared meanings that is based on a signifying order, a complex system of different types of signs that cohere in predictable ways into patterns of representation which individuals and groups can utilize to make or exchange message" (Danesi and Perron 1999: 67).

(Budaya adalah sistem makna bersama yang didasarkan pada suatu tatanan yang berarti, sebuah sistem yang kompleks dari berbagai jenis tanda yang melekat dalam cara diprediksi menjadi pola-pola representasi individu dan kelompok yang dapat menggunakan untuk membuat atau pertukaran pesan)

Kehidupan praktis sehari-hari didominasi oleh konsep hubungan. Setiap orang mengenal dirinya sendiri atas dasar perbedaannya dengan orang lain di sekitarnya. Dua individu yang berbagi budaya umum didasari oleh etnis, agama, atau bahkan politik akan cenderung memiliki model mental yang berkorelasi sehingga memfasilitasi komunikasi (Sethi dan Yildiz, 2017: 1). Proses dan sistem komunikasi didasarkan atas terjadinya berbagai bentuk hubungan, baik dalam ruang maupun waktu. Perubahan status peranan didasarkan atas perubahan polapola hubungan sosial. Dinamika-dan dengan demikian keberlangsungan kehidupan-itu sendiri pun diakibatkan melalui terjadinya perubahan hubungan.
Sebagai replika kehidupan, karya sastra memanfaatkan energi antar-hubungan dalam membangun totalitas. Melalui medium bahasa, pengarang menyajikan unsur-unsur fisik, sebagai fabula. Antarhubungan, yaitu melalui imajinasi pembaca, mengubah cerita sehingga menyerupai kehidupan, dalam bentuk plot. Antar-hubungan mengimplikasikan unsur-unsur kebudayaan sehingga khazanah suatu kebudayaan dapat dipahami oleh komunitas yang lain. Dengan demikian, keberhasilan sebuah karya sastra juga ditentukan oleh kemampuan penulis dalam menyajikan keberagaman antar-hubungan.

Dalam teori dan pelaksanaan pada praktik, terdapat sisi-antara (interface) yang harus diteliti secara tuntas-agar dengan pengetahuan yang diperoleh lebih lanjut dari telitian itu, konsekuensi dalam penerapan praktis dapat dikendalikan secara ketat (Masinambow 2004: 2). Pendapat tersebut mengindikasikan bahwa sasaran pokok yang hendak dicapai lebih bersifat akademis, yaitu memperoleh pemahaman tentang prinsip-prinsip dan konsep-konsep dasar yang melandasi pandangan-pandangan teoretis tentang kebudayaan. Melalui pemahaman tersebut, dapat diperoleh akses ke kepustakaan teoretis sehingga diperoleh wawasan yang membantu dalam merancang dan melaksanakan penelitian. Teori-teori kebudayaan yang dibahas meliputi pandangan bahwa kebudayaan (1) sebagai sistem adaptasi terhadap lingkungan; (2) sebagai sistem tanda; (3) 
sebagai teks, baik yang memahami polapola perilaku budaya secara analogis dengan wacana tekstual, maupun yang mengkaji hasil proses interpretasi teks sebagai produk kebudayaan; (4) sebagai fenomena yang mempunyai struktur dan fungsi; dan (5) menurut perspektif filsafat (hlm. 3). Dalam meninjau manusia sebagai sasaran observasi konkrit, terdapat lima jenis data untuk dianalisis, yakni artefak, perilaku kinetis, perilaku verbal, tuturan, dan teks. Isu kompleks yang dapat dihimpun yakni hubungan antara konteks, struktur, dan fungsi dalam studi naratif terhadap identitas yang melingkupinya (Mishler 2006: 30).

Pembedaan antara ilmu pengetahuan budaya, ilmu pengetahuan sosial, dan ilmu pengetahuan budaya merupakan permasalahan awal yang dibahas. Kontras yang terlihat jelas adalah jika ilmu pengetahuan budaya dipertentangkan dengan ilmu pengetahuan alam, mengingat bahwa bidang tersebut memusatkan perhatian pada alam dibandingkan dengan manusia sebagai pusat perhatian ilmu pengetahuan budaya. Manusia dalam hubungan tersebut diartikan sebagai makhluk budaya hasil perkembangan historis, bukan sebagai makhluk biologis hasil evolusi alamiah. IImu pengetahuan alam (Naturwissenschaften) dalam proses penelitian berupaya untuk menemukan hukum-hukum alam sebagai sumber dari fenomena alam. Pendekatan yang digunakan dalam ilmu pengetahuan alam disebut "nomotetis" atau "ilmiah", dalam arti yang sempit. Hal itu dibedakan dengan pendekatan "ideografis" sebagai ancangan khas berkaitan dengan ilmu pengetahuan budaya (Kulturwissenschaften) (Masinambow 2004: 4). Dalam hubungan ilmu pengetahuan budaya dan ilmu pengetahuan sosial terdapat kekaburan batas sebagai bentuk implikasi dari konsep "kebudayaan" pada satu pihak dan "masyarakat" di pihak lain. Kontras antara ilmu pengetahuan budaya dan ilmu pengetahuan sosial tidaklah tajam, kedua bidang itu sering dinamakan dengan satu istilah, yaitu ilmu pengetahuan manusiawi (human sciences).

Prinsip-prinsip dasar yang dijadikan titik tolak untuk memahami kebudayaanmembuat teori kebudayaan-adalah yang berasal dari Ferdinand de Saussure (1857-1913), Charles Sanders Peirce (1839-1914), dan teori interpretasi teks. Menurut Saussure, tanda (dalam bahasa) terdiri atas penanda (signifiant, signifier) dan petanda (signifié, signified); penanda adalah citra bunyi, sedangkan petanda adalah gagasan atau konsep. Hubungan antara individu dan masyarakat dalam bahasa diungkapakan Saussure melalui gagasan langue dan parole, pasangan beroposisi tersebut dikenal dengan konsep diadik. Berbeda dengan Saussure, konsepkonsep Peirce dibagi menjadi tiga komponen, yaitu representament, object, dan interpretant, dikenal dengan istilah triadik. Dalam interpretasi suatu teks terdapat dua prinsip penting, yaitu (1) lingkaran hermeneutik, dan (2) pendirian bahwa teks mengandung makna tunggal 
(textual monosemy) atau makna majemuk (textual polysemy). Menurut Winfried Noth (1990: 331), teks mengungkapkan pesan-pesan budaya yang berbeda dengan definisi beragam bahwa teks mengungkapkan pesan-pesan verbal. Oleh karena definisi tersebut, terdapat berbagai pandangan yang berbeda, yakni teks dan wacana merupakan dua sinonim; teks adalah yang tertulis, sedangkan wacana adalah yang lisan; dan teks adalah struktur abstrak yang terwujud ke dalam wacana sebagai tuturan nyata. Noth (1990: 295) mengutip Fages, mengemukakan bahwa terdapat tujuh kaidah analisis struktural, yakni imanensi, pertinensi, komutasi, kompatibilitas, intergrasi, diakronis, dan fungsi. Kaidah-kaidah tersebut yang kemudian menjadi ciri dari analisis struktural. Penerapan satu atau beberapa di antaranya sudah memperlihatkan bahwa analisis suatu kajian berciri struktural (Hoed 2007: 20).

Pada beberapa perkembangan mutakhir, poststrukturalisme melangkah lebih jauh. Makna substansial pada hakikatnya tidak ada, artinya tidak berakar pada dunia empiris yang berada di luar tanda. Makna yang pasti baru terwujud dalam kaitan dengan suatu wacana tertentu dan makna itu akan mengalami perubahan atau mempunyai nilai berlainan dalam konteks wacana yang berbeda. Pada aliran pascamodern, terdapat suatu usaha untuk mempertahankan gagasan-gagasan yang bermula dalam Pencerahan, dengan kesadaran penuh tentang kekurangan, penyimpangan dan kemunculan berbagai paradoks yang telah menjadi sasaran kecaman tajam oleh para penganut yang menentangnya.

Pascamodernitas berkembang bersama majunya industri yang memungkinkan konsumsi barang dan jasa secara luas. Dengan demikian, perkembangan mutakhir dalam teori kebudayaan memberikan dinamika pemahaman yang beragam, baik ataupun buruknya tergantung dari pengaplikasian teori tersebut untuk kemajuan masyarakat.

\section{STRUKTURALISME DAN PERKEMBANGANNYA}

Secara definitif, semiotik berasal dari kata seme, bahasa Yunani, yang berarti penafsir tanda. Literatur lain menjelaskan bahwa semiotik berasal dari kata semeion, yang berarti tanda. Dalam pengertian yang lebih luas, sebagai teori, semiotik berarti studi sistematis mengenai produksi dan interpretasi tanda, bagaimana cara kerjanya, dan apa manfaatnya terhadap kehidupan manusia. Kehidupan manusia dipenuhi oleh tanda, dengan perantaraan tanda-tanda proses kehidupan menjadi lebih efisien, dengan perantaraan tandatanda manusia dapat berkomunikasi dengan sesamanya, sekaligus mengadakan pehaman yang lebih baik terhadap dunia, dengan demikian manusia adalah homo semioticus.

Buku Saussure yang terkenal berjudul Cours de Linguistique Generale (1917) dianggap sebagai asal-muasal Strukturalis, sekaligus menempatkan teori bahasa, yaitu linguistik sebagai bagian 
integral teori-teori komunikasi dan keseluruhan hubungan sosial. Dalam hubungan inilah Saussure tidak dianggap sebagai semata-mata ahli dalam bidang ilmu bahasa, melainkan juga sebagai ahli semiotik kebudayaan dan antroposemiotik. Konsep-konsep Saussure terdiri atas pasangan beroposisi, tanda yang memiliki dua sisi, sebagai dikotomi, seperti penanda (signifier, significant, semaion) dan petanda (signified, signifie, semainomenon), ucapan individu (parole) dan bahasa umum (langue), sintagmatis dan paradigmatis, dan diakroni dan sinkroni. Penanda dan petanda dianggap sebagai konsep Saussure yang terpenting. Penanda, gambaran akustik adalah aspek material sebagaimana bunyi, sebagai citra akustis yang tertangkap pada saat orang berbicara. Petanda adalah aspek konsep. Penanda dan petanda memperoleh arti dalam pertentangannya dengan penanda dan petanda yang lain. Hubungan antara penanda dan petanda memperoleh arti dalam pertentangannya dengan penanda dan petanda yang lain. Hubungan antara penanda dengan petanda bersifat arbitrer. Konsep lain adalah perbedaan antara ekspresi kebahasaan (parole, speech, utterance) dan sistem pembedaan di antara tanda-tanda, sistem yang digunakan oleh semua orang (langue, language). Parole bersifat konkret yang kemudian membentuk sistem bahasa yang lebih bersifat abstrak, yaitu langue. Langue dengan demikian dianggap sebagai fakta sosial, sebagai ciri-ciri institusi, impersonal, gudang tanda, sistem kebahasaan yang dipahami bersama, individu tidak dapat mengubahnya, melainkan harus mempelajarinya dan kemudian mentaatinya. Langue diumpamakan sebagai bahasa nasional atau sebagai kamus yang dimiliki oleh semua anggota masyarakat, di mana setiap orang dapat mencari perbendaharaan kata-kata untuk melakukan suatu komunikasi. Menurut Saussure, komunikasi dapat berjalan dengan lancar dengan syarat ditaatinya aturan yang dipahami bersama-dalam hubungan ini struktur dan fungsi. Strukturalisme itu sendiri merupakan upaya untuk memikirkan kembali segala sesuatu dalam hal linguistic (Eagleton dalam Sanusi, 2012: 126).

Perkembangan strukturalisme kontinuitas ala Saussure dapat dilihat dalam bidang antropologi melalui Claude Levi-Strauss. Melalui kajian sistem kekerabatan, Levi-Strauss menggambarkan bahwa unsur-unsur yang menjadi bagian dari sistem itu membentuk jejaring yang membedakan satu sama lain. Makna dari setiap unsur itu tidak sekedar merupakan label, tetapi merupakan hasil dari jejaring diferensiasi di antara unsurunsur itu. Jadi, terdapat bangun yang disebut struktur, namun juga sekaligus di dalam jejaring sistem kekerabatan. Benny H. Hoed (2007 : 22) menyatakan bahwa hal penting yang dapat dilihat yakni adanya kontinuitas dalam konsep struktur dan sistem sehingga meskipun ada perkembangan, strukturalisme masih hadir dalam sosok yang pernah dikemukakan Saussure. 
Kemudian, perkembangan strukturalisme mengalami suatu evolusi. Hal tersebut mengimplikasikan bahwa terdapat perubahan evolusioner dari kaidah-kaidah strukturalisme-salah satu tokohnya adalah Julia Kristeva. Fokus perhatian Kristeva adalah pada teks. Menurut Kristeva (1980) teks bukanlah sesuatu yang statis, tak bergerak; teks bukan sekedar turunan kaidah-kaidah langue. Ketika bahasa menjadi teks, maka teks menjadi berlawanan secara dialektis dengan langue. Hal ini terjadi karena teks mengandung dua aspek, yakni "aspek pemaknaan" dan "aspek produktivitas" (Hoed 2007: 25-26). Aspek praktik pemaknaan (signification) mengandung pengertian pemaknaan yang tidak tunggal karena praktik kebahasaan sifatnya bersubjek plural, pluribahasa, dan polifonis. Teks memiliki makna yang secara potensial tak terhingga yang diberikan oleh subjeknya. Hal tersebut terjadi karena subjek dalam praktik kebahasaan bukanlah satu dan yang utama. Subjek bahasa hanyalah medium perantara bahasa. Teks pada hakikatnya bermakna plural dan pluralitas makna itu bersumber pada bahasa sendiri yang memiliki sifat tersebut. Akibatnya, teks (sebagai manifestasi parole) dapat berlawanan dengan langue, yakni tidak selalu mengikuti langue. Dengan demikian, Kristeva menolak konsep langue Saussurean dengan cara bergerak ke arah subjek yang berbicara, sebagai subjek linguistik, subjek yang terpecah dan terdesentralisasi (Moi 1985 : 152).
Lebih jauh lagi, perkembangan strukturalisme model Saussure telah berkembang menjauhi sumbernya. Salah satu tokoh yang melakukan pembongkaran bahasa sebagai otonomisasi tulisan adalah Jacques Derrida. Dia melihat bahasa bersumber pada tulisan (ecriture). Tulisan adalah bahasa yang secara maksimal memenuhi dirinya sendiri karena tulisan menguasai ruang secara maksimal. Derrida berlawanan pendapat dengan Saussure mengenai pengutamaan bahasa lisan. Derrida berpendapat bahwa tulisan memiliki otonomi dan tidak sekedar derivat dari bahasa lisan. Tulisan merupakan bahasa yang memenuhi dirinya sendiri tanpa tergantung pada bahasa lisan. Dia mendorong subjek pembicara untuk melakukan penundaan secara sadar sebagai tindakan berpikir kritis. Dalam proses pemahaman makna, tanda hadir bukan sekadar karena ada proses oposisi atau diferensiasi, tetapi karena ada proses "penundaan" hubungan penanda dan petanda untuk menemukan makna lain atau makna baru (Hoed 2007: 29). Proses tersebut dikenal dengan proses dekonstruksi (Derrida 1976). Kesemua hal itu merupakan pondasi untuk memahami konstruksi budaya.

\section{KONSTRUKSI BUDAYA}

Kajian budaya (cultural studies) merupakan gerakan keilmuan dan praksis kebudayaan yang melihat secara kritis kompleksitas teori-teori budaya-yang penuh dengan bias kepentingan elit budaya dan kekuasaan. Oleh karena 
sifatnya yang kritis, tidak mengherankan jika kemudian kajian budaya memiliki sifat disiplin dan metodologi yang berbeda dengan ilmu-ilmu pasti yang umumnya disipliner (Pickering 2008: 1-2). Dalam hal tersebut, kajian budaya lebih bersifat eklektis-sehingga banyak yang menganggap batas-batas kajian budaya menjadi kabur.

Secara historis, kajian budaya dapat dirunut pada gerakan mazhab Frankfrut yang sejak dini memperkenalkan teori kritis. Teori kritis tersebut bersifat emansipatoris dan senantiasa curiga. Melalui kata kunci kritis itu teori budaya mengambil semangatnya. Dengan semangat kritis, kajian budaya melihat lebih dalam pada fenomena budaya yang selama ini terpinggirkan. Selain itu, ciri interdisiplineritas kajian budaya juga terkait pada perkembangan teori-teori poststruktural (West 2003: 260). Dengan semangat interdisipliner, kajian budaya menemukan dukungan metodologis dari berbagai disiplin ilmu dan pendekatanpendekatan baru untuk menajamkan analisisnya. Hal itu turut membantu penghancuran sekat pemisah antar disiplin ilmu dalam kajian budaya. ${ }^{1}$ Seperti halnya penjabaran dari Stuart Hall (1996: 262), "Cultural studies is a discursive formation, in Foucault's sense. It has no simple origins, though some of us were present at some

1 Melani Budianta (2003: 16) mengatakan, "Di tengah hiruk pikuk politik identitas di media massa, kita perlu membagi pengalaman lintas batas, pengalaman interpersonal yang mengatasi tembok pemisah antar kelompok. Di tengah percaturan yang point when it first named itself in that way".

Konstruksi menjadi istilah penting untuk memahami budaya melalui kaca mata kajian ilmu pengetahuan budaya. Hubungan antara dunia dan sistem simbolik secara kritis dibongkar agar dapat dipahami secara mendalam. Kepentingan serta strategi kebudayaan dipandang sebagai konstruksi yang membentuk definisi kebudayaan. Oleh karena itu, eksplorasi terhadap masalah-masalah persepsi dan pengetahuan tidak dapat terlepas dari pengertian ideologis dan politis. Ideologi turut memainkan peran dalam pembentukan makna yang berlaku di dalam suatu sistem. Masyarakat turut berperan dalam menciptakan makna yang berlaku, Benedict Anderson (1983: 15) memaparkan, "Communities are to be distinguished, not by their falsity/ genuineness, but by the style in which they are imagined".

Strategi-strategi pelaku budaya menafsirkan dunia kebudayaan tidaklah bersifat universal dan absolut. Dunia kebudayaan pada kenyataannya dikelilingi oleh konteks sosial, politik, dan ekonomi tertentu. Konteks-konteks tersebut didasarkan pada sebuah ideologi, yakni seperangkat praktik budaya, wacana, ritual, dan keyakinan yang mengarah kepada pembiasan-baik individu maupun komunitas-pandangan dunia yang

haus kekuasaan, kita perlu menampilkan pahlawanpahlawan multikultural... Dan yang terpenting... kita memerlukan keberanian untuk mendengar yang kita tidak sukai, belajar dari yang kita tidak pahami dan berdialog dengan yang berseberangan". 
dominan. Pada saat pelaku (subjek) budaya menafsirkan dunia dengan cara tertentu, maka secara bersamaan ideologi turut mengkonstruksi subjektivitas penafsir. Dengan demikian, identitas sosial selaku komponen dari struktur kekuasaan dan pengetahuan menjadi saling terkait dengan individu.

Sosialisasi ${ }^{2}$ politik dan sosialisasi psikologi atas individu-individu berfungsi sebagai instrumen pemeliharaan ideologi, pelestarian cara menafsirkan dunia, dan konstruksi makna yang dihadirkan. Prosedur-prosedur ideologi dan pandangan dunia yang dipelihara tidaklah seragam. Ideologi bersandar pada beragam sistem tanda: pesan tertulis, pesan lisan, seni visual, media, kode perilaku, dan konvensi ritual. Sistem yang dibentuk tersebut merupakan hasrat dalam pelabelan identitas tertentu kepada suatu budaya. Ketentuan-ketentuan yang ditetapkan seakan memberi kesan untuk mengikat dan melindungi ideologi terhadap sang "Lain" (the Other). Strategi yang ditujukan untuk mengontrol sang "Lain" kerap kali memasuki wilayah gender dan seksualitas. Hal itu menjadi kritikan tajam Michel Foucault (1998: 81-82) terhadap pendisiplinan tubuh, bahwa kekuasaan mempengaruhi pengetahuan.

Ideologi-ideologi dominan turut memakai nilai-nilai estetika budaya sebagai jaminan mutu dalam konstruksi ideologi. Apresiasi budaya atas keindahan,

\footnotetext{
2 Sosialisasi menjadi tahapan penting dalam pembentukan tradisi. Eric Hobsbawm mengatakan (1983: 9), “...those whose main purpose was
}

gagasan-gagasan budaya atas cita rasa, dan sikap-sikap budaya atas seni dipandang mencerminkan nilai etika dan moral. Hal tersebut tidaklah bersifat netral dan bebas dari penyalahgunaan. Keseluruhan cermin sosial itu dimaksudkan untuk mengembangkan representasi atas lingkup eksistensi budaya. Pada akhirnya, segala sesuatu adalah representasi karena gagasan-gagasan tersebut baru dapat dipahami melalui sistem penandaan yang berterima. Lingkup pengalaman yang melatari pengetahuan individu atau kelompok menjadi fungsi tekstualitas.

Latar itu merupakan mata rantai yang saling menjalin membuat suatu narasi tentang identitas. Validitas mengenai identitas yang disampaikan narasi-narasi tersebut sukar untuk dipastikan. Hal itu disebabkan arus regulasi makna yang terjadi dibentuk oleh bahasa. Bahasa mengandung dimensi figuratif, retorika, dan cenderung distorsif, meskipun narasi yang ditampilkan tampak jelas. Oleh karena itu, representasi dan teks yang menyusun konstruksi budaya cenderung meruntuhkan pembedaan-pembedaan konvensional antara nyata dan tidak nyata, alami dan tiruan (simulation), dunia dan simulacra-nya (Baudrillard 1983: 11).

Ambiguitas makna dalam pertentangannya dengan indentitas adalah perang budaya yang tak berujung. Ketegangan dilematis antara tradisi dan modernitas kerap kali didramatisasi

socialization, the inculcation of beliefs, value systems and conventions of behavior". 
melalui representasi yang problematis tentang sisi-sisi "Lain" dalam konstruksi kebudayaan. Identitas budaya itu dipakai dalam dua lapisan pertukaran: (1) sebagai kompromi sekaligus pembelaan diri ketika memasuki atau membeli budaya modern yang mengglobal, dan (2) komodifikasi identitas budaya (Budianta 2008: 328).

Definisi identitas budaya menjadi kompleks dengan berbagai pertarungan makna yang terjadi. Proses pendefinisian identitas, baik individu maupun kelompok, bukanlah suatu esensi yang tetap, melainkan suatu pengambilan posisi. Pengambilan posisi tersebut tidak pernah selesai, sebagaimana dikatakan Hall (2003: 99), "...it is true that those positionalities are never final, they're never absolute". Sebagai produk budaya yang diciptakan dalam sistem, berbagai versi Si Doel mau tidak mau ikut terlibat di dalam sistem yang menjadi sorotan umum. Teks itu pun menciptakan suatu gambaran tentang kebudayaan Betawi dan bahasanya yang membantu menciptakan sebuah stereotip (Budianta 2008: 323). Konstruksi yang berlaku mengakibatkan kebudayaan Betawi sebagai kawasan uji coba untuk formasi glamornya budaya global di tengah kerinduan akan budaya lokal. Fenomena lintas budaya-seperti ditunjukkan oleh pakar multikultural-tidak dapat dipisahkan dari bingkai kepentingan sosial, politik, dan ekonomi, baik dalam tataran lokal, nasional maupun global (Budianta 2007: 15).

Dalam bidang kesusastraan dan keseniaan, gerakan multikultural menggugat stereotip-stereotip konstruksi sosial budaya yang rasis dan esensialis. Penulis dan seniman memperlihatkan percampuran budaya, interaksi lintas batas, toleransi, dan identitas yang majemuk dan kompleks untuk mengatasi fanatisme suku, agama, ras, dan kelompok (Budianta 2003: 10). Hal tersebut diperlukan guna menyoroti perspektif monokultural yang dianggap kodrati oleh fanatisme kelompok masyarakat tertentu, yang sebenarnya adalah konstruksi. Negosiasi merupakan strategi toleransi untuk melihat keberagaman budaya sebagai identitas yang cair dalam masyarakat.

\section{SIMPULAN}

Strukturalisme dapat dijelaskan sebagai sebuah sistem penyatu yang mencoba merancang secara ilmiah sebuah spektrum fenomena kultural yang luas menurut model bahasa. Strukturalisme mengakui sifat arbitrer proses-proses di mana tanda memperoleh maknanya, namun Strukturalis percaya bahwa aturanaturan linguistik yang fundamental bersifat universal dan dapat diterapkan universal pula. Dalam konteks poststrukturalisme, realitas tidak semata-mata merupakan konstruksi linguistik, melainkan juga sebuah konsep yang tidak stabil. Bahasa tidak henti-hentinya membentuk kembali dunia dengan beragam cara yang "menakjubkan". Itu menunjukkan bahwa tanda-tanda yang dikonstruksi melalui sejarah, filsafat, kesusastraan dan subjektivitas manusia itu sendiri 
senantiasa terbuka untuk "dimainmainkan". Analogi permainan yang dimaksudkan juga berorientasi pada teks, bukan sekadar penafsiran yang tak berdasar, diistilahkan dengan trajectory (objektivitas teks, hukum yang berlaku). Hal tersebut merupakan bentuk kreativitas manusia dalam mencari pemaknaan terhadap kebudayaan yang terus berubah. Karakter interdisipliner teori budaya telah menjadi objek interpretasi yang bersifat heterogen. Pengertian mengenai kebudayaan senantiasa terbuka untuk didefinisikan kembali, walaupun sebuah budaya-bahkan setiap budayadibentuk oleh masa lalu (tradisi). Namun, kebudayaan sering kali dipertanyakan dan diolah kembali makna serta penafsiran yang telah melekat pada periode tertentu. Konstruksi budaya yang dibentuk oleh masa lalu melalui narasi-narasi bukanlah sebuah jaminan kebenaran yang final. Dengan melihat kebudayaan sebagai sebuah dimensi yang terkait ruang dan waktu serta kepentingan-kepentingan di dalamnya, maka redefinisi menjadi penting untuk dilakukan guna melihat masa depan secara terbuka dan bijak.

\section{REFERENSI}

Anderson, Benedict. (1983). Imagined Communities: Reflection on the Origin and Spread of Nationalism. London dan New York: Verso.

Budianta, Melani. (2008). "Representasi Kaum Pinggiran dan Kapitalisme", Sastra Indonesia Modern Kritik Postkolonial (Ed. Keith Foulcher dan Tony Day). Jakarta: Yayasan Obor Indonesia dan KITLV.

Danesi, Marcel., and Paul Perron. (1999). Analyzing Cultures: An Introduction and Handbook. Bloomington and Indianapolis.

Derrida, Jacques. (1976). Of Grammatology. Baltimore and London: The Johns Hopkins University Press.

Foucault, Michel. (1998). The Will to Knowledge: The History of Sexuality Volume 1 (Trans. Robert Hurley). London: Penguin Books.

Hall, Stuart. (1996). Critical Dialogues in Cultural Studies (Ed. David Morley dan Kuan-Hsing Chen). London dan New York: Routledge. . 2003. "Cultural Studies and Its Theoretical Legacies", The Cultural Studies Reader (Ed. Simon During). London dan New York: Routledge.

Hobsbawm, Eric. (1983). "Introduction: Inventing Tradition", The Invention of Tradition (Eds. Eric Hobsbawm dan Terence Ranger). Cambridge: Cambridge University Press.

Hoed, Benny H. (2007). "Derrida VS Strukturalisme De Saussure", Basis. Nomor 11-12 tahun ke-56.

Kristeva, Julia. (1980). Desire in Language: A Semiotic Approach to Literature and Art. Chicago: Columbia University Press.

Masinambow, E.K.M. (2004). "Teori Kebudayaan dan Ilmu Pengetahuan 
Budaya", Semiotika Budaya. Kemasyarakatan dan Budaya DRPM UI.

Mishler, Elliot G. (2006). "Narrative and identity: the double arrow of time", Discourse and Identity (Eds. Anna De Fina, Deborah Schiffrin, Michael Bamberg). Cambridge: Cambridge University Press.

Moi, Toril. (1985). Sexual/Textual Politics:

Feminist Literary Theory. London and New York: Methuen.

Noth, Winfried. (1990). Handbook of Semiotics. Bloomington and Indianapolis: Indiana University Press.

Pickering, Michael. (2008). Research Methods for Cultural Studies. Edinburgh: Edinburgh University Press.

Sanusi, Ibrahim Chinade. (2012). "Structuralism as a Literary Theory: An Overview". Afrrev Laligens, Vol. 1, 124:131.

Sethi, Rajiv. \& Yildiz, Muhamed. (2017). Culture and Communication. (Research Paper).

West, Cornel. (2003). "The New Cultural Politics of Difference", The Cultural Studies Reader (Ed. Simon During). London dan New York: Routledge.

\section{Bio Penulis}

Dr. Hendra Kaprisma, S.Hum. adalah pengajar di Program Studi Rusia Fakultas IImu Pengetahuan Budaya Universitas Indonesia (FIB UI). Dia menyelesaikan S3 Program Studi IImu Susastra FIB UI dengan jalur khusus-tanpa menempuh jenjang S2-pada tahun 2015. Dia memulai kuliah S3 pada tahun 2009 dengan mengambil beberapa mata kuliah S2 tanpa tesis. Pada tahun 2011 dia mengikuti Sandwich Ph.D. Candidates di Universitas Negeri SaintPetersburg, Rusia. Setahun kemudian (2012), dia kembali lagi ke Rusia untuk penelitian disertasi dengan mendapatkan penghargaan Sylff Research Award dari Tokyo Foundation. 